\title{
Impedance Spectroscopic Investigation of the Degraded Dye-Sensitized Solar Cell due to Ageing
}

\author{
Parth Bhatt, ${ }^{1}$ Kavita Pandey, ${ }^{1,2}$ Pankaj Yadav, ${ }^{3}$ Brijesh Tripathi, ${ }^{4}$ and Manoj Kumar ${ }^{4}$ \\ ${ }^{1}$ Department of Solar Energy, School of Technology, Pandit Deendayal Petroleum University, Gandhinagar 382007, India \\ ${ }^{2}$ Inorganic Chemistry Laboratory, University of Oxford, South Parks Road, Oxford OXI 3QR, UK \\ ${ }^{3}$ Department of Electrical Engineering, Incheon National University, Incheon 406772, Republic of Korea \\ ${ }^{4}$ Department of Science, School of Technology, Pandit Deendayal Petroleum University, Gandhinagar 382007, India
}

Correspondence should be addressed to Manoj Kumar; manoj.kspv@gmail.com

Received 19 July 2016; Accepted 9 November 2016

Academic Editor: Francisco R. Zepeda

Copyright (c) 2016 Parth Bhatt et al. This is an open access article distributed under the Creative Commons Attribution License, which permits unrestricted use, distribution, and reproduction in any medium, provided the original work is properly cited.

\begin{abstract}
This paper investigates the effect of ageing on the performance of dye-sensitized solar cells (DSCs). The electrical characterization of fresh and degraded DSCs is done under AM1.5G spectrum and the current density-voltage $(J-V)$ characteristics are analyzed. Short circuit current density $\left(J_{\mathrm{SC}}\right)$ decreases significantly whereas a noticeable increase in open circuit voltage is observed. These results have been further investigated electroanalytically using electrochemical impedance spectroscopy (EIS). An increase in net resistance results in a lower $J_{\mathrm{SC}}$ for the degraded DSC. This decrease in current is mainly due to degradation of $\mathrm{TiO}_{2}$-dye interface, which is observed from light and dark $J-V$ characteristics and is further confirmed by EIS measurements. A reduction in the chemical capacitance of the degraded DSC is observed, which is responsible for the shifting of Fermi level with respect to conduction band edge that further results in an increase of open circuit voltage for the degraded DSC. It is also confirmed from EIS that the degradation leads to a better contact formation between the electrolyte and Pt electrode, which improves the fill factor of the DSC. But the recombination throughout the DSC is found to increase along with degradation. This study suggests that the DSC should be used under low illumination conditions and around room temperature for a longer life.
\end{abstract}

\section{Introduction}

The metal oxide based dye-sensitized solar cells (DSCs) have attracted significant attention of researchers in recent years, because of their economic fabrication process and efficient working under diffuse illumination. The highest certified device efficiency has reached $11.9 \%$ [1]. A DSC module of large area $\left(100 \mathrm{~cm}^{2}\right)$ has been demonstrated with an efficiency of $8.4 \%$ [2]. The DSC was explicated by O'Regan and Grätzel [3], which operates by exposing dye molecules to light that releases excited electrons to oxidize the dye, which is then restored by electron donation from the redox couples (iodide/triiodide, $\mathrm{I}^{-} / \mathrm{I}_{3}{ }^{-}$) in the electrolyte. The redox couples are then revived by counter electrode with electrons extracted from the working electrode via the external load circuitry. Though the DSCs have demonstrated a highly promising performance instantly, the long term performance plays a major role in the commercialization of a solar PV technology. The poor stability of DSC is mainly directed by the degradation mechanism occurring at different layers of the device after prolonged operation. So, the analysis of the degradation mechanisms within DSC is of great interest to explore the factors affecting the performance of DSCs. Only a few papers present the stability studies of DSC [4-9]. Different techniques have been used to analyze the degradation mechanisms in DSCs; Uam et al. [10] used UVvis absorption spectroscopy to identify that the desorption of dye on the $\mathrm{TiO}_{2}$ surface was the reason for current density reduction in an aged cell. Additionally, Tatay et al. [11] accompanied the UV-vis absorption spectroscopy with luminescence and cyclic voltammetry and observed that organic dyes formed molecular aggregates which could deteriorate the device efficiency. Also, there are few studies which used electrochemical impedance spectroscopy (EIS) 


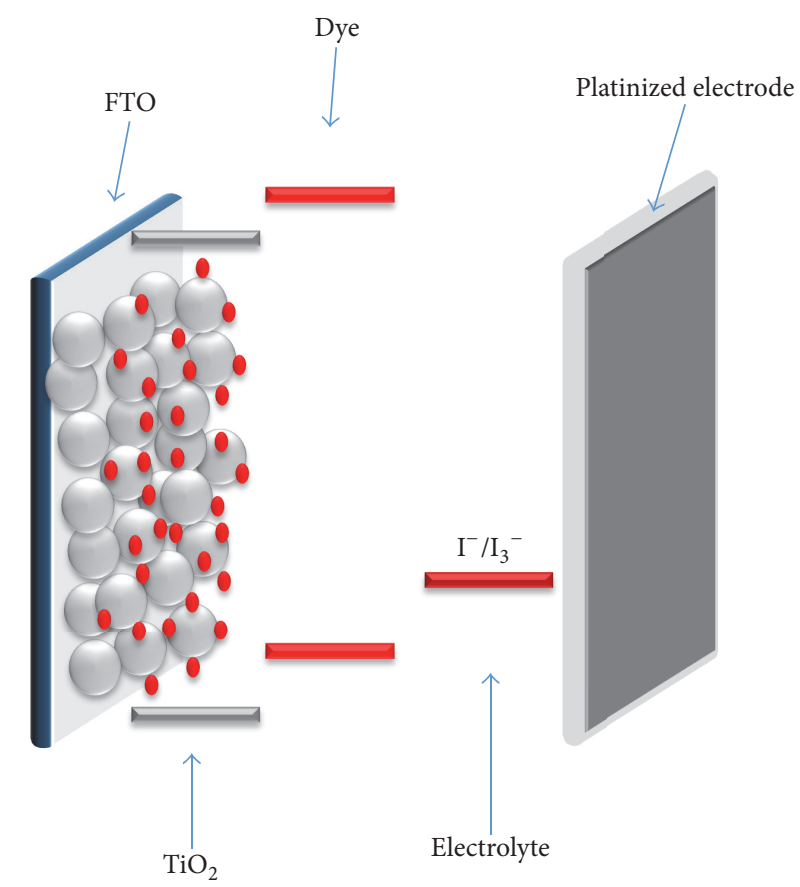

(a) Fresh DSC

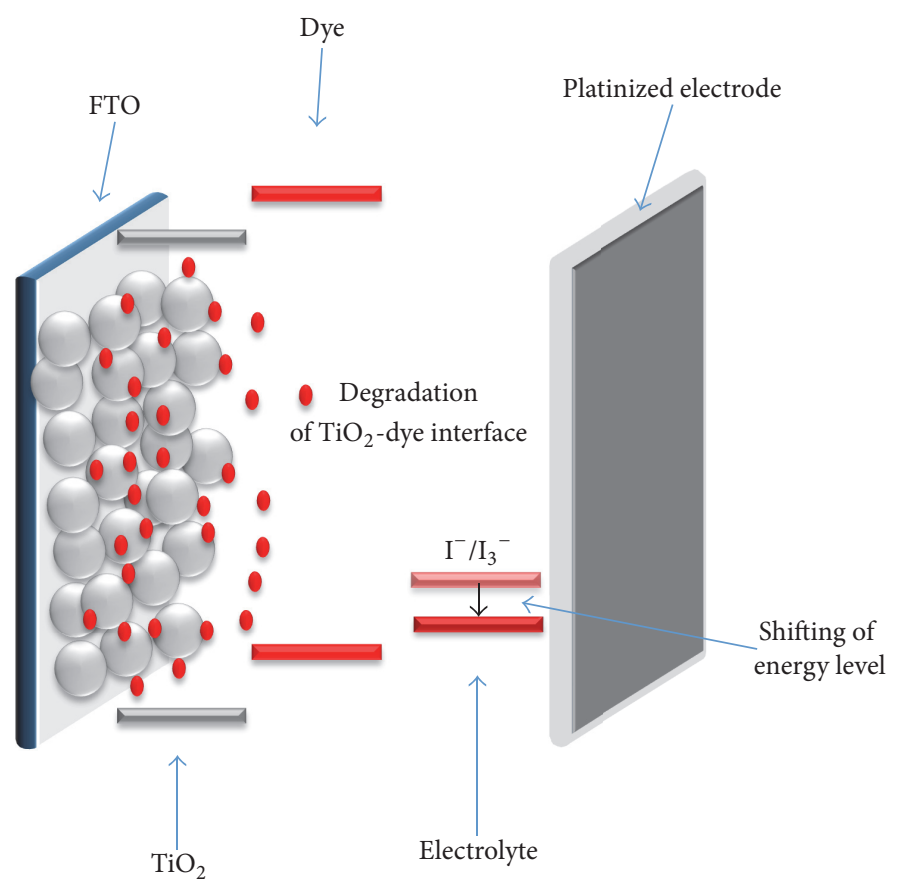

(b) Degraded DSC

FIGURE 1: Schematic diagram representing the components of (a) fresh DSC and (b) degraded DSC.

to investigate degradations in ageing DSCs $[4,8]$ but they lack in-depth understanding on the correlation of electron kinetics with the device performance.

In our previous report, we have analyzed the interfacial losses in large area DSCs [12]. In continuation with previous studies, this article reports the electroanalytical analysis of various degradation mechanisms within DSC of comparatively larger area $\left(=3.78 \mathrm{~cm}^{2}\right)$ for a gap of 45 days using the EIS technique. A schematic diagram to show the mechanisms of degradation in the reported DSC is shown in Figure 1.

\section{Experimental}

The details of the fabrication of DSCs are discussed in our previous work [12]. In short, FTO thin films, about $1 \mathrm{~mm}$ thick, were spray-deposited on Corning glass sheets. Silver grid lines (with $12 \mathrm{~mm}$ intervals) were deposited on the above FTO using Ag paste. Mesoporous $\mathrm{TiO}_{2}$ was deposited between silver grids after which the samples were dipped into a $3 \mathrm{mM}$ solution of $\mathrm{N} 719$ dye for $12 \mathrm{~h}$. Counter electrodes were prepared by lightly sputtering Pt $(50 \mathrm{~nm})$ on $1.1 \mathrm{~mm}$ thick titanium metal plates. For each cell, photoelectrodes and counter electrodes were sandwiched, and UV was irradiated to cure the sealant while using a mask to cover the dye coated area. The active area of the fabricated cell is $3.78 \mathrm{~cm}^{2}$ (fabricated by SPD laboratory, Japan).

The photovoltaic measurements were carried out using a solar simulator (Photoemission Tec SS80AAA with 1.5AMG filter) and a source measuring unit (U2722A, Agilent). A three-electrode potentiostat (CHI 660D) equipped with a general purpose software was used for the EIS measurements.
The working electrode was connected to the positive terminal of the cell whereas the counter electrode and reference electrode were shorted and connected to the negative terminal of the DSC. An AC perturbation signal of $10 \mathrm{mV}$ (root-meansquare voltage) was applied in the frequency range of $10 \mathrm{mHz}$ to $1000 \mathrm{kHz}$ during the EIS measurements. The inductive effect between the connecting leads and the potentiostat were taken care of during the experiments.

\section{Results and Discussion}

3.1. J-V Analysis. Figures 2(a) and 2(b) depict the light and dark $J-V$ characteristics of a fresh and degraded DSC, respectively. As received DSC shows a power conversion efficiency $(\eta)$ of $4.0 \%$, short circuit current density $\left(J_{\mathrm{SC}}\right)$ of $9.92 \mathrm{~mA} / \mathrm{cm}^{2}$, open circuit voltage $\left(V_{\mathrm{OC}}\right)$ of $0.65 \mathrm{~V}$, and fill factor (FF) of $60.9 \%$, but after degradation $\eta$ reduces to $3.6 \%$ with $J_{\mathrm{SC}}$ of $7.74 \mathrm{~mA} / \mathrm{cm}^{2}, V_{\mathrm{OC}}$ of $0.685 \mathrm{~V}$, and $\mathrm{FF}$ of $67 \%$. From the above observation, it is clear that the drop in $J_{\mathrm{SC}}$ has played a vital role in degradation of the device. This significant loss in $J_{\mathrm{SC}}$ in the degraded cell may be attributed to the increased recombination and resistive losses in the device. In DSCs, the recombination loss is mainly associated with (i) electron recombination from $\mathrm{TiO}_{2}$ conduction band and deep and shallow level traps to the electrolyte and (ii) electron recombination from the uncovered layer of FTO to the electrolyte [13]. Conversely, the resistive losses are mainly linked to the resistance at $\mathrm{FTO}-\mathrm{TiO}_{2}$ interface, resistance due to the diffusion of redox species in the electrolyte, the charge transfer resistance at platinized counter electrode-electrolyte interface, and sheet resistance of FTO $[14,15]$. 


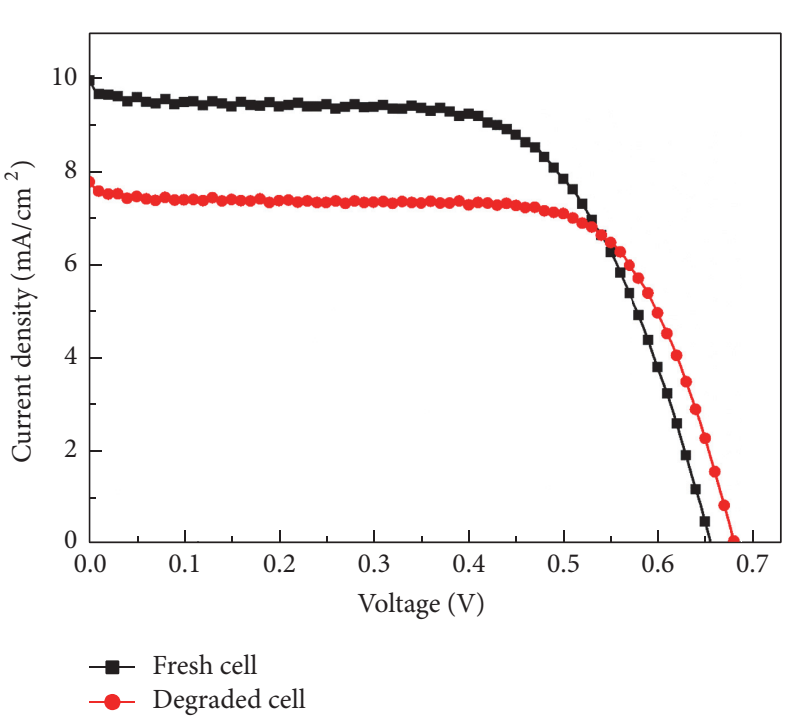

(a)

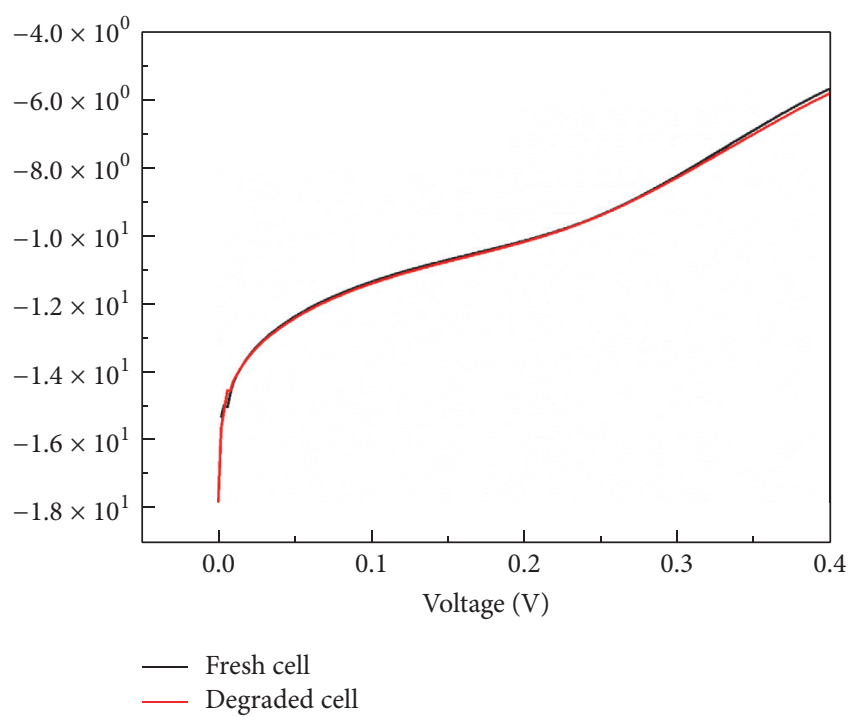

(b)

FIgUre 2: (a) Current density-voltage $(J-V)$ characteristics of fresh DSC and degraded DSC. (b) Dark $J-V$ for fresh and degraded DSC.

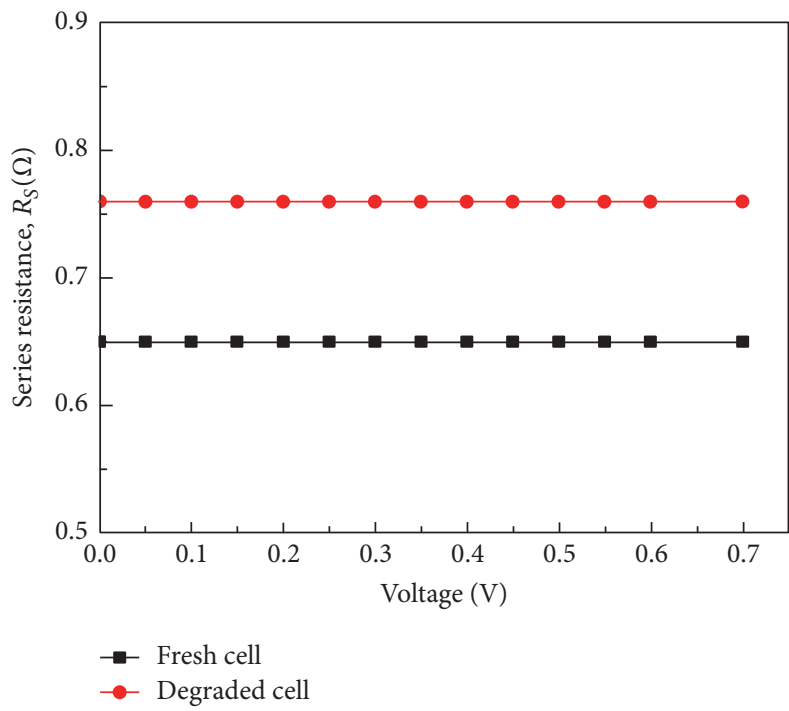

(a)

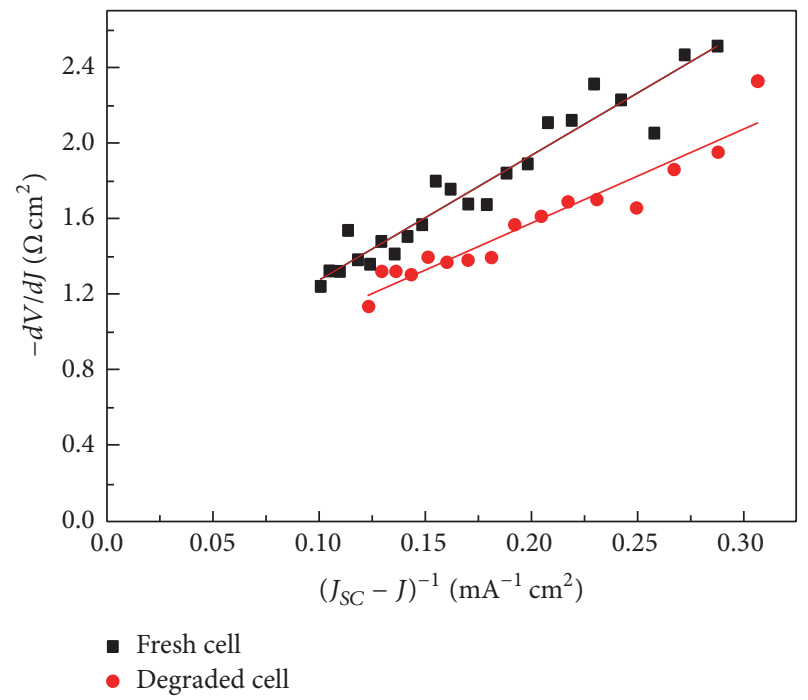

(b)

FIgURE 3: (a) $R_{S}$ of both cells calculated by EIS. (b) $R_{S}$ of both cells calculated by light $J-V$.

$V_{\mathrm{OC}}$ and FF have been surprisingly observed to improve along with the degradation of the cell. The improvement in FF can be ascribed to the formation of better contact between the electrolyte and Pt electrode along with degradation [16]. The increase in $V_{\mathrm{OC}}$ of degraded DSC has been observed by Lai et al. [4]. The increase can also be attributed to greater photon flux received by the dye, the reduction of $\mathrm{I}^{3-}$ concentration, or reduction of dye cation concentration.

To get further understanding about the degradation of DSC, the $J-V$ characteristics are calculated by $J=J_{0} \exp ((q V+$ $\left.\left.J R_{S}\right) / m k_{B} T\right)-J_{S C}$, where $J_{0}$ is the dark exchange current, $R_{S}$ is the series resistance, $m$ is the diode ideality factor which depends on the rate of recombination reaction of electrons, oxidized species in the electrolyte, and the distribution of recombination sites [17], and $q, k_{B}$, and $T$ represent the electronic charge, Boltzmann's constant, and cell temperature, respectively. The equation above can be reduced as (considering $J_{0}$ as negligible to $\left.J_{\mathrm{SC}}\right) d V / d J=R_{S}+\left(m k_{B} T / q\right)$. $\left(1 /\left(J_{\text {SC }}-J\right)\right)[18,19]$.

Figure 3(a) shows plot of $-d V / d J$ versus $\left(J_{\mathrm{SC}}-J\right)^{-1}$ for fresh and degraded DSCs in which a linear fit is made to the experimental data to estimate the values of $m$ and $R_{S}$. For fresh DSC $\mathrm{m}$ and $R_{S}$ are obtained to be 1.18 and $0.65 \Omega \mathrm{cm}^{2}$ and for degraded DSC they are obtained as 1.22 and $0.76 \Omega \mathrm{cm}^{2}$, respectively. Figure 3(b) shows plot of $R_{S}$ versus voltage for fresh and degraded DSCs. The increase in 


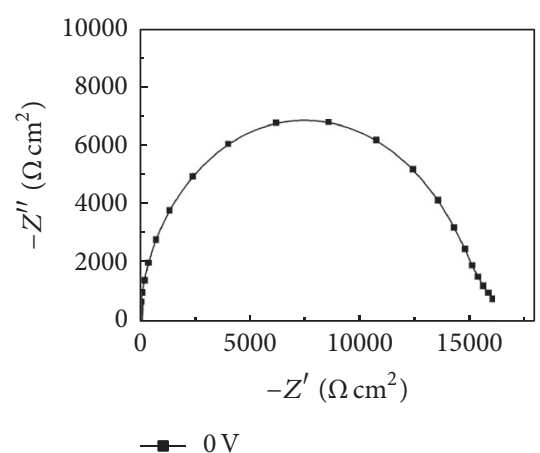

(a)

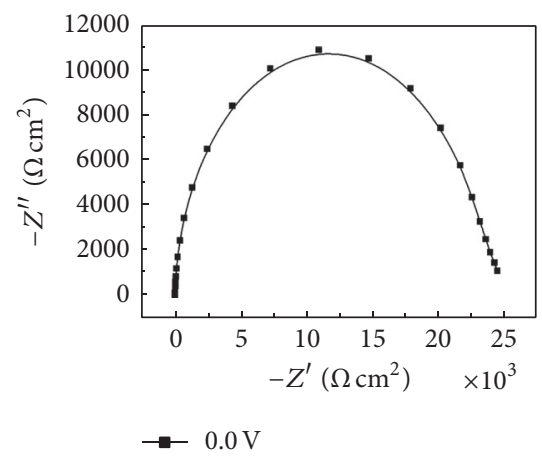

(d)

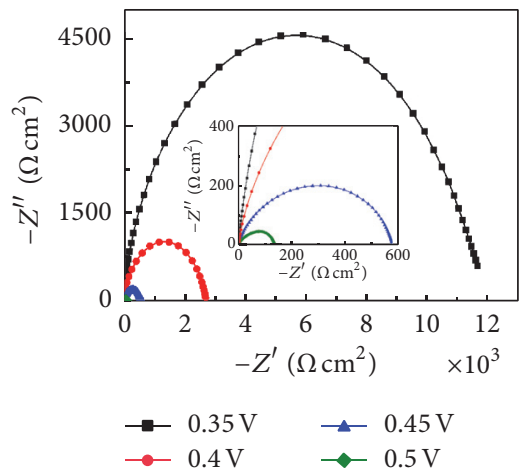

(b)

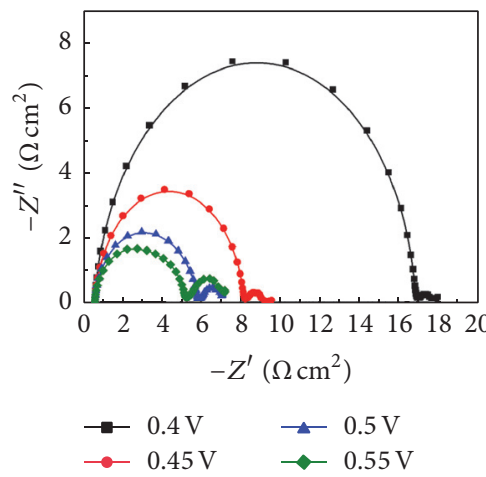

(e)

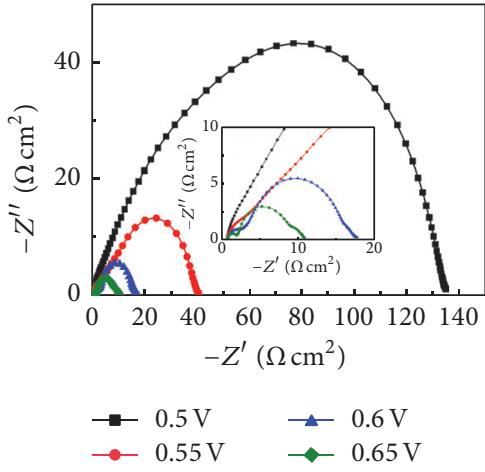

(c)

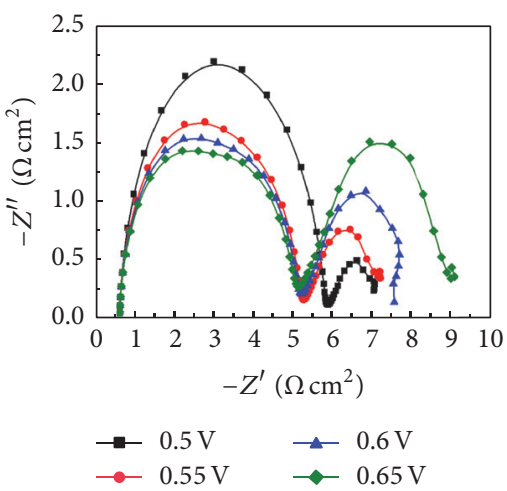

(f)

FIgURE 4: Nyquist plot for fresh DSC (a) at 0 bias, (b) near knee voltage, and (c) near $V_{\mathrm{OC}}$, respectively. Nyquist plot for degraded DSC (d) at 0 bias, (e) near knee voltage, and (f) near $V_{\mathrm{OC}}$, respectively.

$R_{S}$ of $0.12 \Omega \mathrm{cm}^{2}$ for the degraded DSC can be considered as one of the possible reasons for increase in resistive losses resulting in lower $J_{\mathrm{SC}}$ in degraded cells. Furthermore, the shunt resistance for the fresh and degraded DSCs is obtained as $1552 \Omega \mathrm{cm}^{2}$ and $2845 \Omega \mathrm{cm}^{2}$, respectively. The increased shunt resistance due to degradation is responsible for improvement in the FF and $V_{\mathrm{OC}}$ of the degraded DSC.

No conclusive evidence for the cause of degradation can be identified solely with analysis of $J-V$ characteristics, as the DSCs have a complex device structure, nonlinear recombination mechanism, and indivisible device parameters. So, in order to have a conclusive evidence for the observed degradation the DC and AC characterizations, that is, impedance spectroscopy (IS) and $J-V$, are combined together.

3.2. EIS Analysis. Electrochemical impedance spectroscopy (EIS) is used to identify the performance limiting factors leading to degradation of DSCs. Using EIS the various physical processes can be modelled (under the appropriate conditions) in terms of resistive and capacitive elements [20]. The aim of this article is to compare the fresh DSC and degraded DSC, which can be done on the basis of selected crucial parameters with a simplified model as compared to the transmission line model. The transmission line model is generally used to describe the working of a DSC in detail, which was not required in this case. The characteristic impedance spectroscopic data measured under dark conditions of the fresh and degraded DSCs depicts the contribution from various charge transport layers as shown in Figure 4. In order to analyze the data the Nyquist plot is used, which shows different arcs to represent different processes occurring within the device with respect to frequency. This method helps in quantifying the dynamic features of the system to compare their values. From the Nyquist plot $\left(Z^{\prime}\right.$ versus $Z^{\prime \prime}$ ) the value of resistance can be estimated by the width of the arc in the real axis. As described in device operation, several interfaces in the DSC involve high level of electron transfer and transport. These processes include charge transport through porous $\mathrm{TiO}_{2}$ layer, electron transfer at $\mathrm{TiO}_{2}$-dye/electrolyte interface, $\mathrm{I}_{3}^{-}$diffusion region in electrolytic medium, and electron transfer at electrolyte/Pt interface. Another important representation is the Bode plot, that is, $|Z|$ versus frequency and phase versus frequency plots. The resistances can be obtained from the plateaus. The important aspect of this plot is that $\omega$ information is not lost.

3.2.1. At 0 Bias. Figures 4(a)-4(f) show the Nyquist plot of the fresh and degraded cells under various bias in dark conditions. The line following the experimental data in Figure 4 represents the theoretical fit. Figures 5(a)-5(f) represent the Bode plots for the fresh and degraded DSCs. The fitting of the experimental data is done using the equivalent circuit as shown in Figure 6(a). At zero bias, that is, when the 


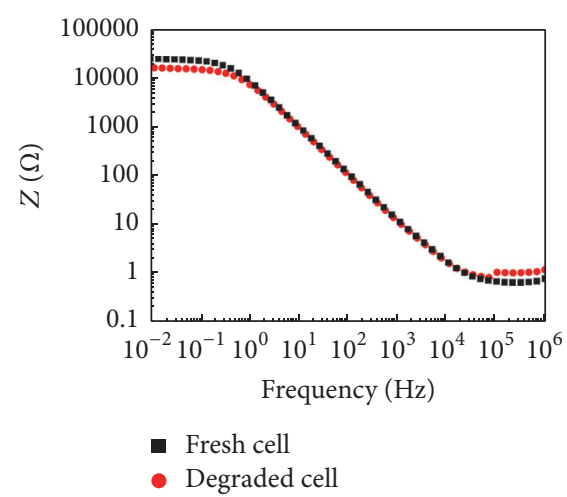

(a)

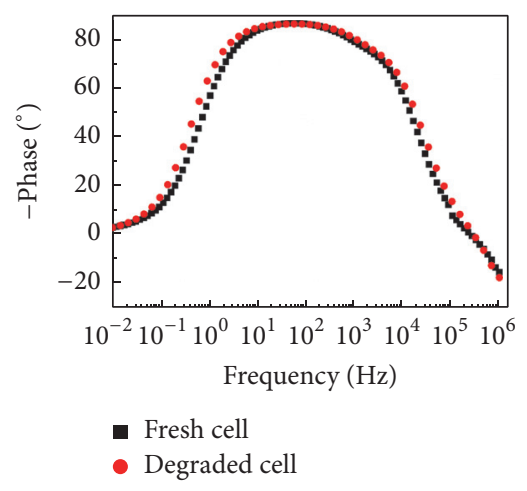

(d)

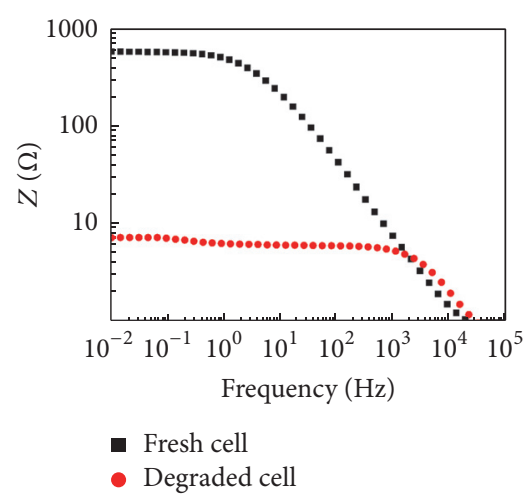

(b)

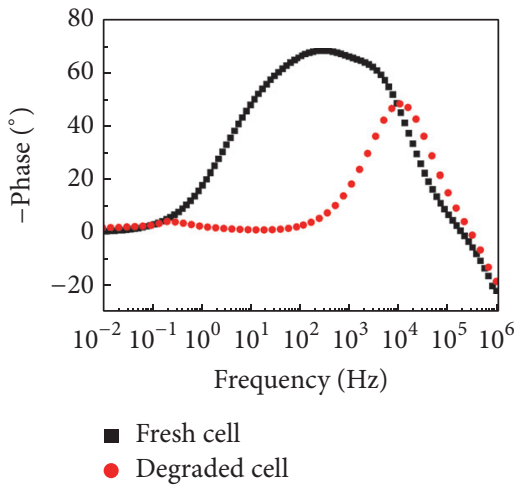

(e)

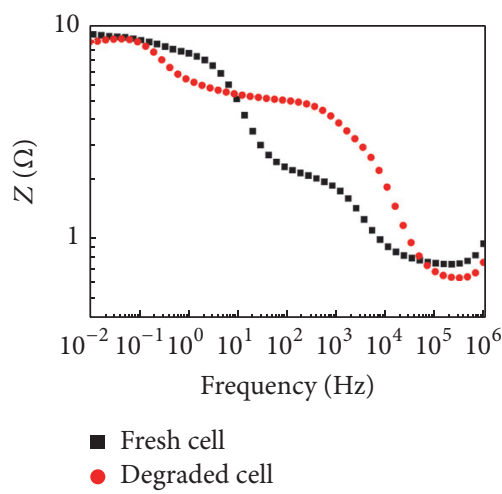

(c)

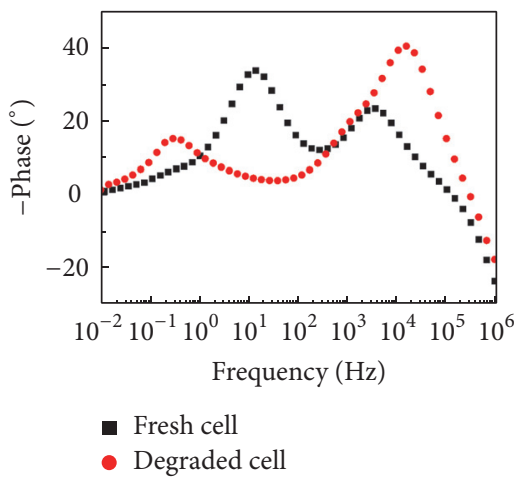

(f)

FIGURE 5: Bode plots for fresh and degraded DSC (a-d) at 0 bias, (b-e) at knee voltage, and (c-f) at $V_{\text {OC }}$, respectively.

device is under nonconducting state, a standard Nyquist plot is observed for fresh DSC [21]. But, for a degraded DSC there is an increase in magnitude of impedance, which can be attributed to increase in $R_{1}$ (at FTO-TiO 2 interface). $R_{S}$ for the fresh and degraded DSC from the EIS measurements are estimated to be $0.63 \Omega \mathrm{cm}^{2}$ and $0.78 \Omega \mathrm{cm}^{2}$, respectively, which are well in agreement with that obtained from $J-V$ measurements. Figure 5(a), that is, the Bode plot at zero bias, shows the change in $R_{S}$. The height of the plateau region for the degraded cell has increased which depicts change in $R_{1}$ as observed in impedance. Also the change in height of the plateau shows change in $R_{1}$. Xue et al. [8] have showed that increase in resistance $R_{1}$ is caused due to formation of cracks in $\mathrm{TiO}_{2}$ photoelectrode. The Bode plot of phase versus frequency follows almost a similar trend for both the fresh and degraded DSCs.

\subsubsection{At Knee Voltage (the Voltage at Maximum Power Point).} The EIS for the DSCs near knee yields two semicircles with their frequencies corresponding to $\mathrm{TiO}_{2}$-dye/electrolyte and electrolyte/Pt, but the dominant semicircle represents $\mathrm{TiO}_{2}{ }^{-}$ dye/electrolyte medium which depicts the Nyquist feature of Gerischer element and overall impedance of the cell decreases with increase in bias $[22,23]$. The Gerischer element originates from the $\mathrm{FB}$ reduction of $\mathrm{I}_{3}{ }^{-}$ions by electrons from the conduction band of $\mathrm{TiO}_{2}(1 / 2) \mathrm{I}_{3}^{-}+\mathrm{e}^{-}\left(\mathrm{TiO}_{2}\right)=(3 / 2) \mathrm{I}^{-}$ [24]. It can be clearly observed from the EIS for the fresh and degraded cells that resistance $R_{2}$ (resistance at $\mathrm{TiO}_{2}$ dye/electrolyte interface) has reduced dramatically for the degraded devices. This reduction in $R_{2}$ can be attributed to reduction in electron collection from $\mathrm{TiO}_{2}$ to FTO electrode. In the Bode plot at knee voltage (Figure 5(b)), the slope for degraded cell changes dynamically, which shows the increase in $R_{2}$. Furthermore, electron lifetime $\left(\tau_{e}\right)$ can be estimated from Figure 5(e) using the relation $\tau_{e}=1 / 2 \pi f_{\max }[24,25]$, where $f_{\max }$ represents peak frequency. $\tau_{e}$ for fresh DSCs is observed to be higher than that for degraded samples. This reduction in $\tau_{e}$ reduces the diffusion of the $\mathrm{I}^{3-}$ ions in electrolyte, which increases the concentration of $\mathrm{I}^{3-}$ ions at the $\mathrm{TiO}_{2}$-dye/electrolyte interface, which further increases the recombination leading to degradation in performance of DSCs.

3.2.3. Near Open Circuit Voltage. The Nyquist plot near $V_{\mathrm{OC}}$ shows three semicircles representing all three regions within the device. Interestingly for the degraded DSCs with increasing bias the circle representing $\mathrm{TiO}_{2}$-dye/electrolyte interface decreases and that for electrolyte/Pt interface increases. In the Bode plot we observe two characteristic peaks: the peak at lower frequency corresponds to the $\mathrm{TiO}_{2}$-dye/electrolyte interface and that at high frequency corresponds to electrolyte/Pt interface. The peak for $\mathrm{TiO}_{2}$-dye/electrolyte interface is lower for degraded DSC as compared to fresh ones corresponding to reduction in charge transfer at the interface. 


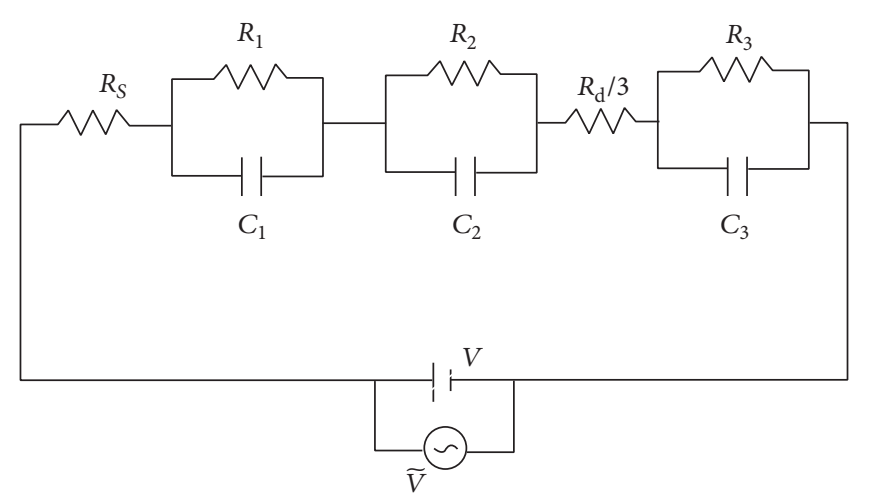

(a)

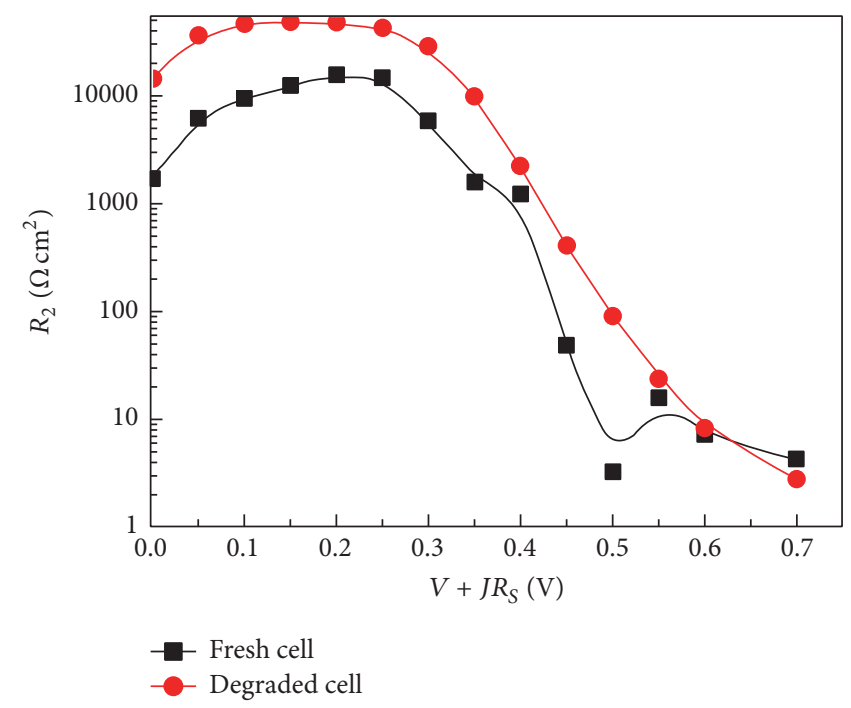

(c)

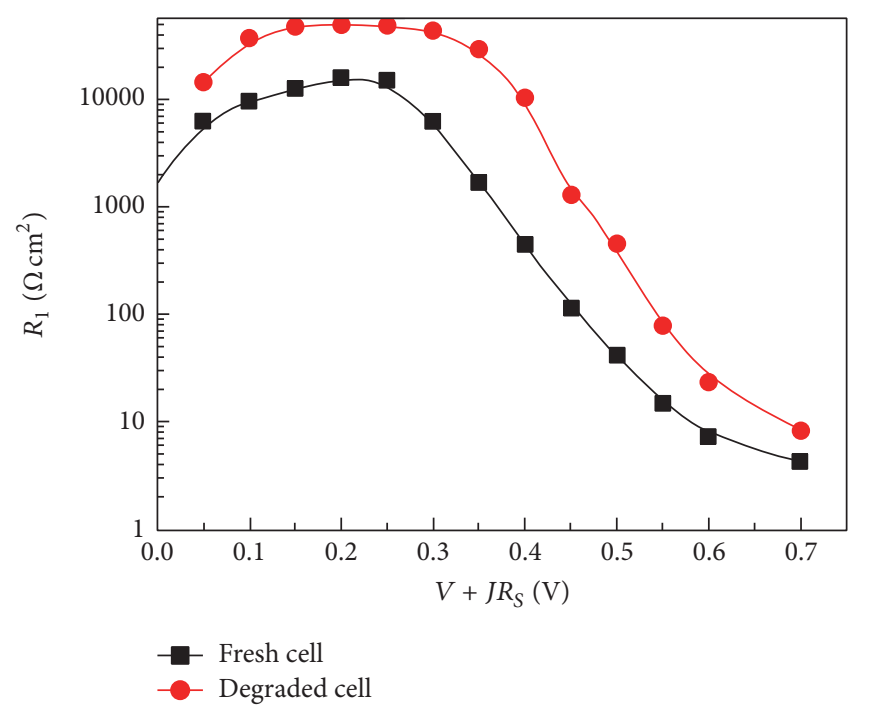

(b)

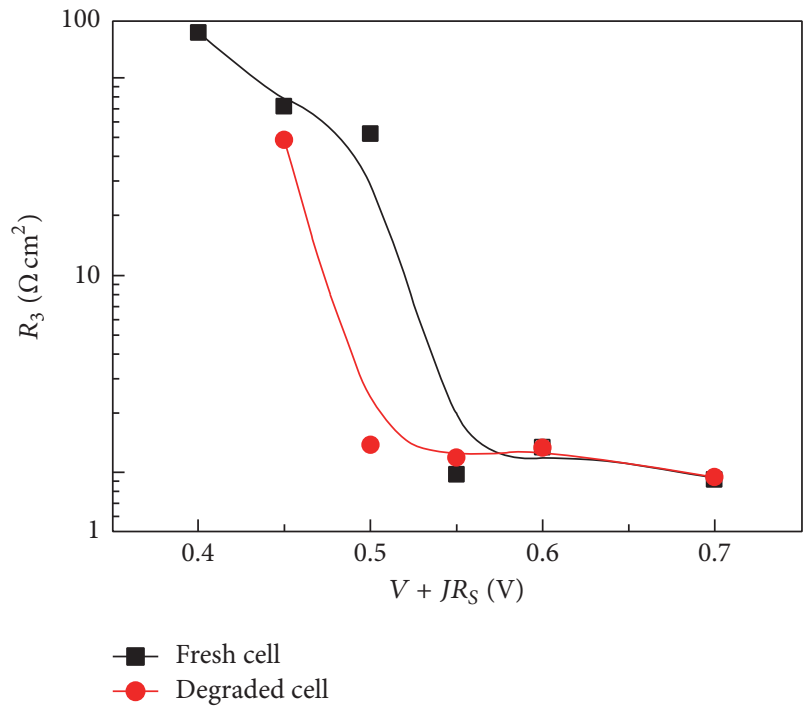

(d)

FiguRE 6: (a) Equivalent circuit used for fitting EIS. Variation of resistances (b) $R_{1}$, (c) $R_{2}$, and (d) $R_{3}$ as a function of applied bias, respectively.

While comparing the Nyquist plots for fresh and degraded DSC for electrolyte/Pt interface, we observe a higher peak for the degraded DSC, which validates better charge transfer at the interface. Hence we can say that degradation of DSC leads to better contact formation between the electrolyte and Pt. This better contact formation is further responsible for higher $\mathrm{FF}$ and $V_{\mathrm{OC}}$ for the degraded DSC [16].

Figures 6(b)-6(d) show the plots for $R_{1}, R_{2}$, and $R_{3}$ versus voltage for the fresh and degraded cells. The lower value of $R_{1}$ for degraded cell throughout the bias in Figure 6(b) is one of the reasons for the reduction in $J_{\mathrm{SC}} \cdot R_{2}$ for degraded cell is higher than fresh cell till $V_{\text {OC }}$, beyond which it decreases, which signifies low charge transfer within the device for the degraded DSCs. Interestingly, $R_{3}$ (resistance at electrolyte/PtFTO interface) for the degraded cells is observed to be lower than that for the fresh ones. This reduction in $R_{3}$ may be attributed to better charge transfer between the electrolyte and $\mathrm{Pt}$, which validates the observation in Bode plot and further justifies the enhancement in FF and $V_{\mathrm{OC}}$ due to degradation. The sum of all resistances, $R_{1}+R_{2}+R_{3}$, gives rise to higher net series resistance resulting in lower $J_{\mathrm{SC}}$. With increasing resistance a drop in chemical capacitance, $C_{2}$, is observed within the device signifying lower electron injection into the conduction band of $\mathrm{TiO}_{2}$. Bisquert [20] showed a direct dependence of $C_{2}$ on the difference between the positions of electron Fermi level with respect to the conduction band. The lower value of $C_{2}$ results in shifting of the Fermi level towards the conduction band edge, which further results in increase in $V_{\mathrm{OC}}$ due to degradation.

Bisquert and Mora-Seró [25] have indicated that the electron back recombination rate $(U)$ is nonlinear in a DSC. This nonlinear nature of the recombination can be represented 


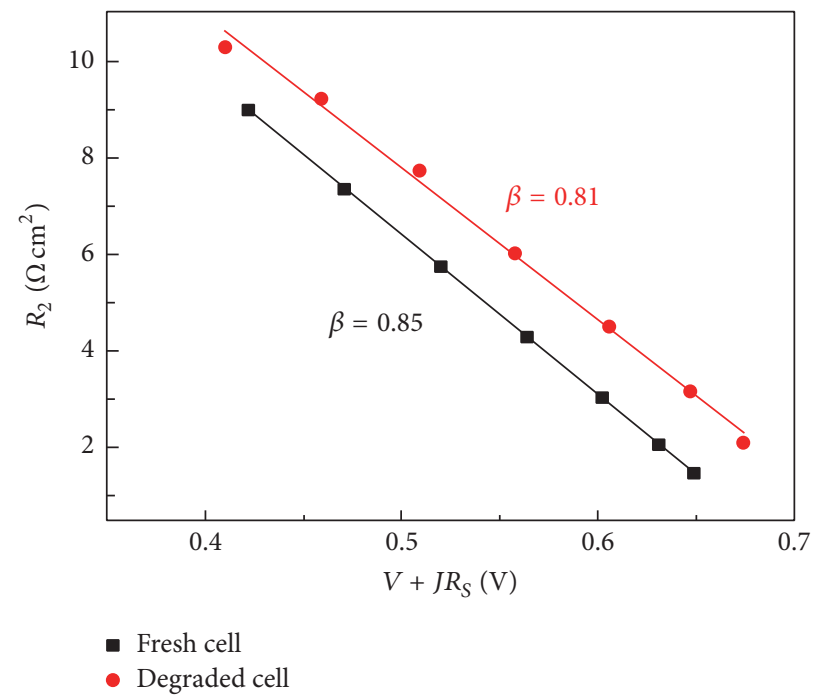

(a)

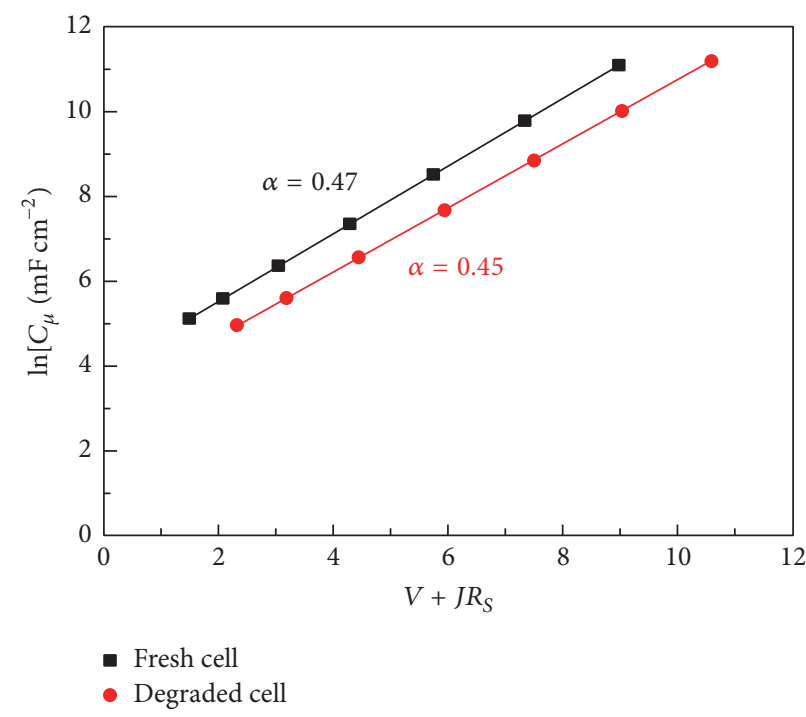

(b)

FIGURE 7: Comparative plot for (a) recombination resistance and (b) chemical capacitance for fresh and degraded DSC, respectively. The line indicates theoretical fit.

using the reaction rate $\beta$, which is expressed as $U=k_{r} n^{\beta}$, where $k_{r}$ is a constant and $n$ is free electron density. The order of recombination, $\beta$, ranges from 0 and 1 . A recombination order of 1 indicates a simple unimolecular recombination via conduction band states. Generally, for DSCs a recombination order of the range between 0.6 and 0.8 is observed [26, 27]. The detailed role and estimation of $\beta$ in DSCs are reported in our previous work [12]. The plot for estimation of $\beta$ is shown in Figure 7(a). The $\beta$ values for fresh and degraded DSCs are estimated as 0.85 and 0.81 , respectively. Sarker et al. [27] have expressed the dependence of $V_{\mathrm{OC}}$ on $\beta$ as $V_{\mathrm{OC}}=$ $\left(k_{B} T / q \beta\right) \ln \left(J_{P H} / J_{0}\right)$. From the above equation it can be stated that the decrease in $\beta$ along with degradation is responsible for the decrease in charge collection due to recombination and also for increase in $V_{\text {OC }}$.

As reported by Wang et al. [21], the chemical capacitance $C_{2}$ can be expressed as $C_{2}=C_{0} \exp \left(-\alpha q V_{F} / k_{B} T\right)=$ $C_{0} \exp \left(-q V_{F} / k_{B} T_{0}\right)$, where $\alpha$ is related to the exponential trap distribution of electrons below the conduction band or it is simply a band gap modulation factor. The plot of $\ln C_{2}$ versus applied bias for the fresh and degraded DSC is shown in Figure $7(b)$. The linear fit of the graph provides the value of $\alpha$. The value of $\alpha$ for fresh and degraded DSC is obtained as 0.47 and 0.45 , respectively. The decrease in $\alpha$ again proves the shifting of Fermi level as observed in EIS, which is responsible for increase in $V_{\mathrm{OC}}$ and fill Factor along with the degradation of DSC.

The net terminal $J-V$ characteristic of DSC is given by [28]

$$
\begin{aligned}
J_{\text {cell }}= & J_{\mathrm{ph}}-J_{0}\left[\exp \left(\frac{q \beta\left(V+j_{\text {cell }} R_{S}\right)}{k_{B} T}\right)-1\right] \\
& -\frac{V_{\text {cell }}+j_{\text {cell }} R_{S}}{R_{\mathrm{SH}}}
\end{aligned}
$$

TABLE 1: Parameters used for simulating the experimental $J-V$ curve for fresh and degraded DSC.

\begin{tabular}{lcc}
\hline Parameters & Fresh DSC & Degraded DSC \\
\hline $\begin{array}{l}\text { Series resistance, } R_{S} \\
\left(\Omega \mathrm{cm}^{2}\right)\end{array}$ & 0.65 & 0.76 \\
$\begin{array}{l}\text { Photocurrent density, } \\
J_{\mathrm{ph}}\left(\mathrm{mA} / \mathrm{cm}^{2}\right)\end{array}$ & 9.73 & 7.64 \\
$\begin{array}{l}\text { Order of } \\
\text { recombination, } \beta\end{array}$ & 0.85 & 0.81 \\
$\begin{array}{l}\text { Reverse saturation } \\
\text { current, } J_{0}\left(\mathrm{~A} / \mathrm{cm}^{2}\right)\end{array}$ & $2.23 E-07$ & $1.59 E-07$ \\
\hline
\end{tabular}

where the term $J_{0}\left[\exp \left(q \beta V_{j} / k_{B} T\right)-1\right]$ indicates the dependence of charge transfer current on the applied voltage and can be approximated through simplified Butler-Volmer equation $[22,29]$ which is essentially the same as the diode equation describing the dark $J-V$ characteristics. The parameters extracted from the EIS measurements of the fresh and degraded DSCs are listed in Table 1. Using these parameters and equation above the simulated $J-V$ was generated and fitted on the experimental data. The fitting of simulated and experimental $J-V$ for fresh and degraded DSC is shown in Figure 8. A good fit of the experimental data suggests a very good evaluation of the performance parameters from the EIS measurements, which further validates the conclusions driven.

\section{Conclusions}

This paper investigates the effect of environmental parameters on the performance degradation of DSC. The electrical characterization of fresh and degraded DSC is done under AM1.5G spectrum and the current-voltage characteristics 


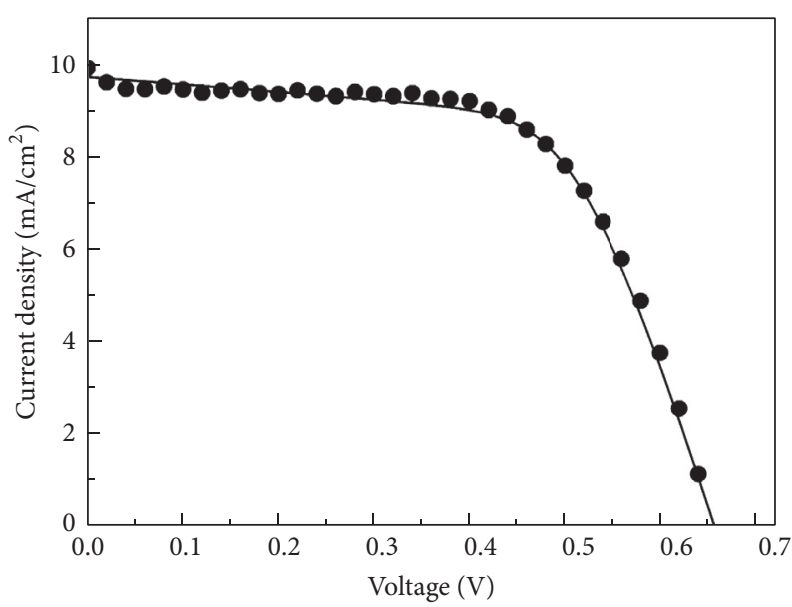

- Experimental

- Theoretical

(a)

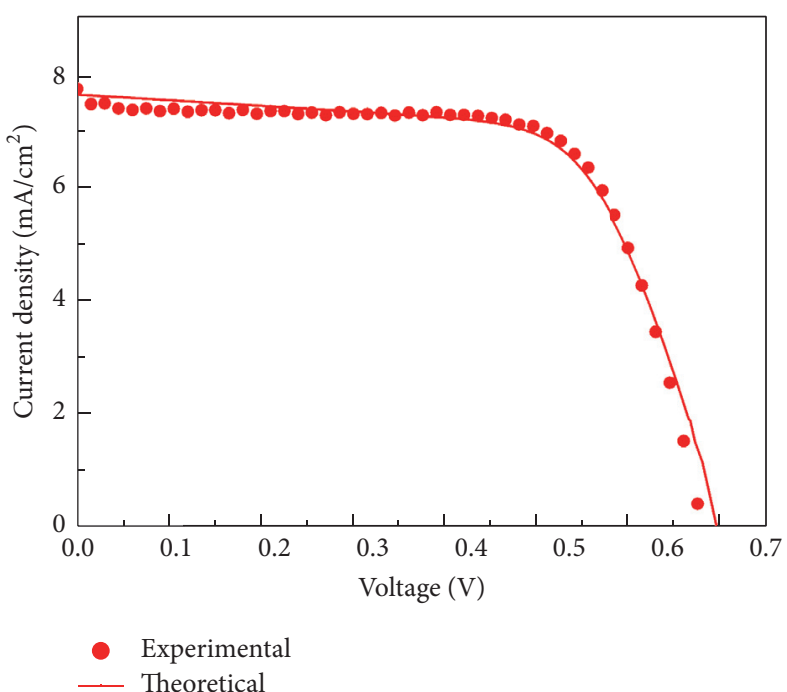

(b)

FIGURE 8: Experimental and theoretical fit for $J-V$ characteristics of (a) fresh and (b) degraded DSC, respectively.

are analyzed. The short circuit current decreases significantly whereas a noticeable increase in open circuit voltage is observed. These results have been further investigated using electrochemical impedance spectroscopic techniques. It is found that the decrease in current is mainly due to dissociation of dye molecules with respect to exposure to ambient environmental conditions, which is confirmed by dark I-V analysis. The increase in $V_{\mathrm{OC}}$ is attributed to Fermi level realignment which is investigated by impedance spectroscopy in the range of applied bias from $-0.7 \mathrm{~V}$ to $0 \mathrm{~V}$. It is found that recombination increases along with ageing of DSC. The study suggests that DSC should be used under low illumination conditions and around room temperature.

\section{Competing Interests}

The authors declare that they have no competing interests.

\section{Acknowledgments}

The authors Parth Bhatt and Kavita Pandey would like to acknowledge Solar Research and Development Centre (SRDC), School of Solar Energy, PDPU, and Department of Science and Technology INSPIRE fellowship program for providing financial support, respectively. The authors would like to acknowledge S. Kaneko, SPD laboratories (Hamamatsu, Japan), for providing DSC used in this article.

\section{References}

[1] M. A. Green, K. Emery, Y. Hishikawa, W. Warta, and E. D. Dunlop, "Solar cell efficiency tables (version 47)," Progress in Photovoltaics: Research and Applications, vol. 24, no. 1, pp. 3-11, 2016.
[2] F.-T. Kong, S.-Y. Dai, and K.-J. Wang, "Review of recent progress in dye-sensitized solar cells," Advances in OptoElectronics, vol. 2007, Article ID 75384, 13 pages, 2007.

[3] B. O’Regan and M. Grätzel, "A low-cost, high-efficiency solar cell based on dye-sensitized colloidal $\mathrm{TiO}_{2}$ films," Nature, vol. 353, no. 6346, pp. 737-740, 1991.

[4] S. C. Lai, K. N. P. Connor, and L. Ke, "Degradation mechanisms and electron kinetics analysis in aging dye sensitized solar cell using electrochemical impedance spectroscopy," Journal of the Electrochemical Society, vol. 158, no. 12, pp. H1193-H1200, 2011.

[5] P. D. Lund, G. Hashmi, Y. Ma, J. Patakangas, and Y. Jing, "Degradation and stability of nanostructured energy devices," Microelectronic Engineering, vol. 126, pp. 49-53, 2014.

[6] U. Opara Krašovec, M. Bokalič, and M. Topič, "Ageing of DSSC studied by electroluminescence and transmission imaging," Solar Energy Materials and Solar Cells, vol. 117, pp. 67-72, 2013.

[7] D. Pumiglia, M. Giustini, D. Dini et al., "Photoelectrochemical response of DSSCs under prolonged reverse bias and conduction band lowering in Ru-complex-sensitized $\mathrm{TiO}_{2}$," ChemElectroChem, vol. 1, no. 8, pp. 1388-1394, 2014.

[8] G. Xue, Y. Guo, T. Yu et al., "Degradation mechanisms investigation for long-term thermal stability of dye-sensitized solar cells," International Journal of Electrochemical Science, vol. 7, no. 2, pp. 1496-1511, 2012.

[9] F. Li, J. R. Jennings, N. Mathews, and Q. Wang, "Evolution of charge collection/separation efficiencies in dye-sensitized solar cells upon aging: a case study," Journal of The Electrochemical Society, vol. 158, no. 9, pp. B1158-B1163, 2011.

[10] H.-S. Uam, Y.-S. Jung, Y. Jun, and K.-J. Kim, "Relation of $\mathrm{Ru}(\mathrm{II})$ dye desorption from $\mathrm{TiO}_{2}$ film during illumination with photocurrent decrease of dye-sensitized solar cells," Journal of Photochemistry and Photobiology A: Chemistry, vol. 212, no. 2-3, pp. 122-128, 2010.

[11] S. Tatay, S. A. Haque, B. O'Regan et al., "Kinetic competition in liquid electrolyte and solid-state cyanine dye sensitized solar 
cells," Journal of Materials Chemistry, vol. 17, no. 29, pp. 30373044, 2007.

[12] P. Yadav, K. Pandey, B. Tripathi, P. V. V. Jayaweera, S. Kaneko, and M. Kumar, "Electroanalytical investigation of the losses during interfacial charge transport in dye-sensitized solar cell," Solar Energy, vol. 129, pp. 207-216, 2016.

[13] X. Xu, K. Cao, D. Huang, Y. Shen, and M. Wang, "Disulfide/thiolate based redox shuttle for dye-sensitized solar cells: An Impedance Spectroscopy Study," Journal of Physical Chemistry C, vol. 116, no. 48, pp. 25233-25241, 2012.

[14] T. Hoshikawa, M. Yamada, R. Kikuchi, and K. Eguchi, "Impedance analysis of internal resistance affecting the photoelectrochemical performance of dye-sensitized solar cells," Journal of the Electrochemical Society, vol. 152, no. 2, pp. E68E73, 2005.

[15] M. S. Góes, E. Joanni, E. C. Muniz et al., "Impedance spectroscopy analysis of the effect of $\mathrm{TiO}_{2}$ blocking layers on the efficiency of dye sensitized solar cells," Journal of Physical Chemistry C, vol. 116, no. 23, pp. 12415-12421, 2012.

[16] Q. Wang, J.-E. Moser, and M. Grätzel, "Electrochemical impedance spectroscopic analysis of dye-sensitized solar cells," The Journal of Physical Chemistry B, vol. 109, no. 31, pp. 1494514953, 2005.

[17] H. Tian, E. Gabrielsson, P. W. Lohse et al., "Development of an organic redox couple and organic dyes for aqueous dyesensitized solar cells," Energy \& Environmental Science, vol. 5, no. 12, pp. 9752-9755, 2012.

[18] D. J. Crain, S. E. Rock, J. E. Garland, and D. Roy, “Comparison of D.C. and A.C. electro-analytical methods for measuring diode ideality factors and series resistances of silicon solar cells," Current Applied Physics, vol. 13, no. 9, pp. 2087-2097, 2013.

[19] J. Shi, J. Dong, S. Lv et al., "Hole-conductor-free perovskite organic lead iodide heterojunction thin-film solar cells: high efficiency and junction property," Applied Physics Letters, vol. 104, no. 6, Article ID 063901, 2014.

[20] J. Bisquert, "Chemical capacitance of nanostructured semiconductors: its origin and significance for nanocomposite solar cells," Physical Chemistry Chemical Physics, vol. 5, no. 24, pp. 5360-5364, 2003.

[21] Q. Wang, S. Ito, M. Grätzel et al., "Characteristics of high efficiency dye-sensitized solar cells," The Journal of Physical Chemistry B, vol. 110, no. 50, pp. 25210-25221, 2006.

[22] J. E. Garland, D. J. Crain, and D. Roy, "Utilization of electrochemical impedance spectroscopy for experimental characterization of the diode features of charge recombination in a dye sensitized solar cell," Electrochimica Acta, vol. 148, pp. 62-72, 2014.

[23] Á. Pitarch, G. Garcia-Belmonte, I. Mora-Seró, and J. Bisquert, "Electrochemical impedance spectra for the complete equivalent circuit of diffusion and reaction under steady-state recombination current," Physical Chemistry Chemical Physics, vol. 6, no. 11, pp. 2983-2988, 2004.

[24] M. Adachi, M. Sakamoto, J. Jiu, Y. Ogata, and S. Isoda, “Determination of parameters of electron transport in dye-sensitized solar cells using electrochemical impedance spectroscopy," Journal of Physical Chemistry B, vol. 110, no. 28, pp. 13872-13880, 2006.

[25] J. Bisquert and I. Mora-Seró, "Simulation of steady-state characteristics of dye-sensitized solar cells and the interpretation of the diffusion length," The Journal of Physical Chemistry Letters, vol. 1, no. 1, pp. 450-456, 2010.
[26] S. Sarker, H. W. Seo, and D. M. Kim, "Electrochemical impedance spectroscopy of dye-sensitized solar cells with thermally degraded N719 loaded $\mathrm{TiO}_{2}$," Chemical Physics Letters, vol. 585, pp. 193-197, 2013.

[27] S. Sarker, H. W. Seo, and D. M. Kim, "Calculating current density - voltage curves of dye-sensitized solar cells: a straightforward approach," Journal of Power Sources, vol. 248, pp. 739744, 2014.

[28] B. Tripathi, P. Yadav, and M. Kumar, "Charge transfer and recombination kinetics in dye-sensitized solar cell using static and dynamic electrical characterization techniques," Solar Energy, vol. 108, pp. 107-116, 2014.

[29] S. E. Rock, X. Shi, J. E. Garland, and D. Roy, "Experimental considerations for temperature controlled measurements of fast charge recombination times in dye sensitized solar cells using open circuit voltage decay and impedance spectroscopy," Measurement, vol. 53, pp. 71-82, 2014. 

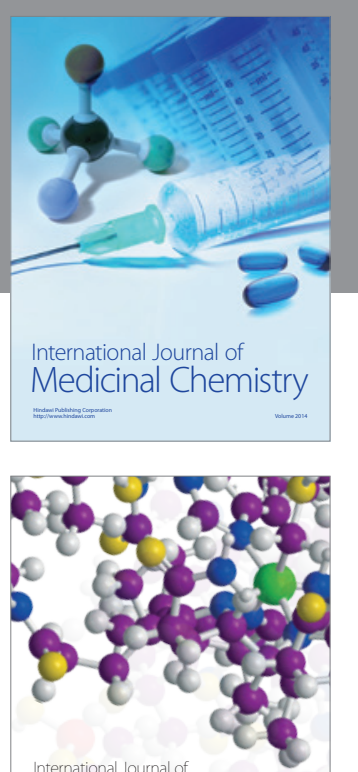

Carbohydrate Chemistry

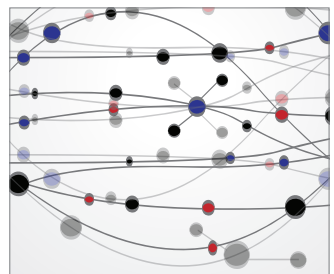

The Scientific World Journal
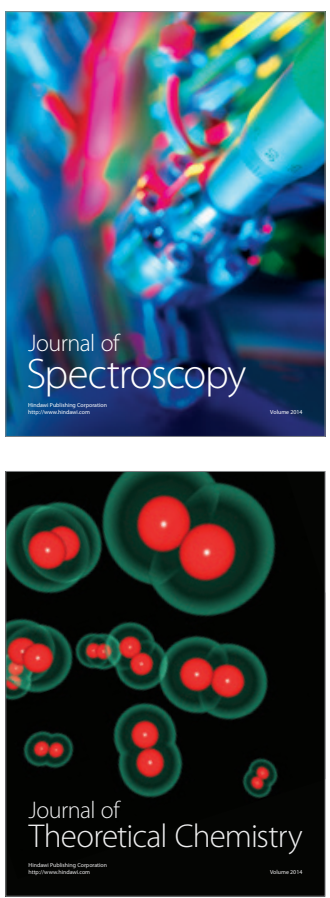
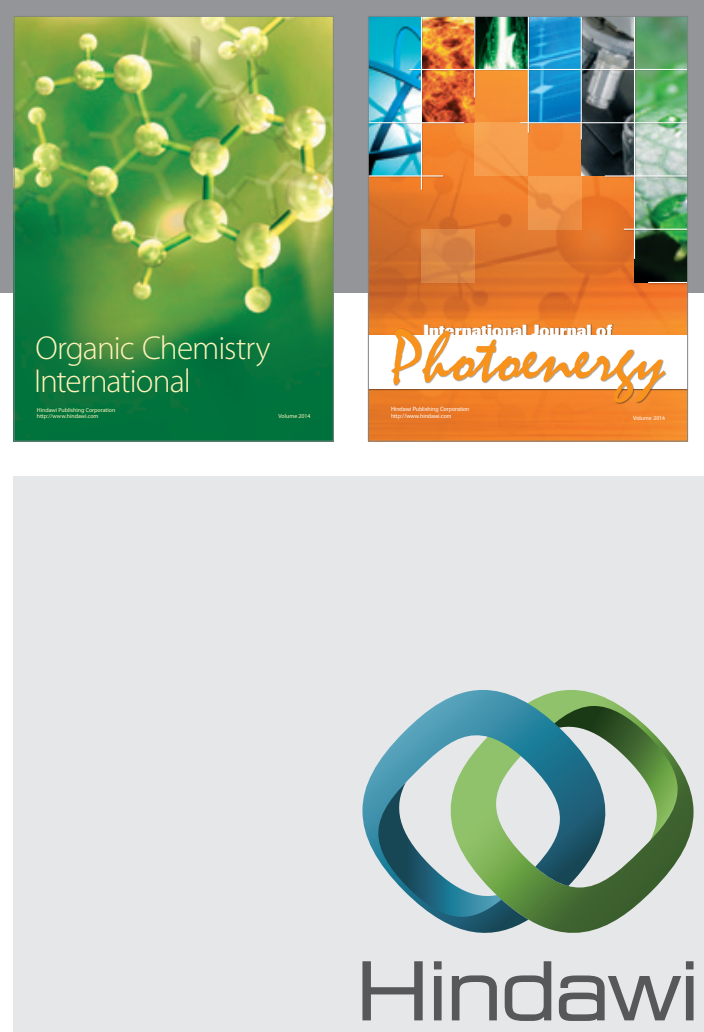

Submit your manuscripts at

http://www.hindawi.com

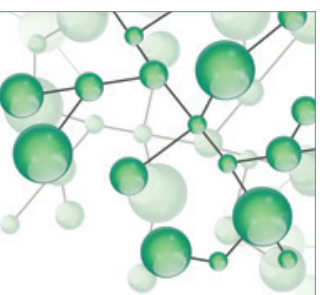

International Journal of

Inorganic Chemistry

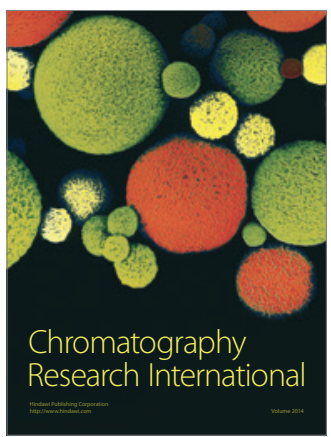

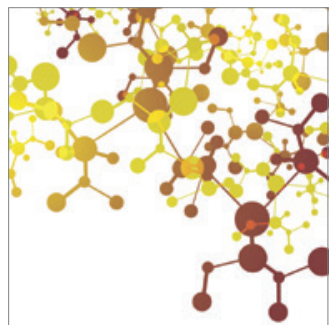

Applied Chemistry
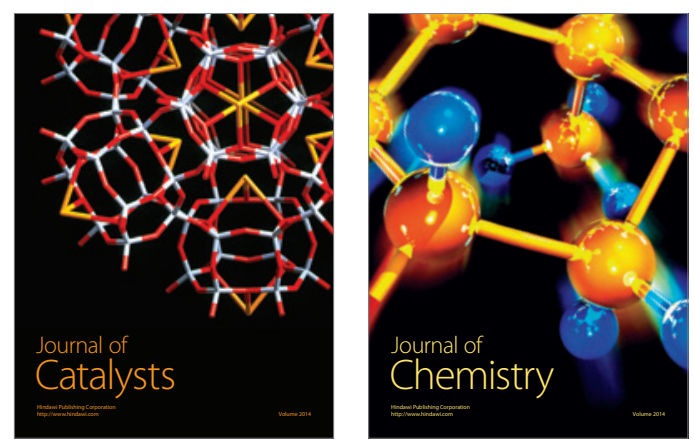
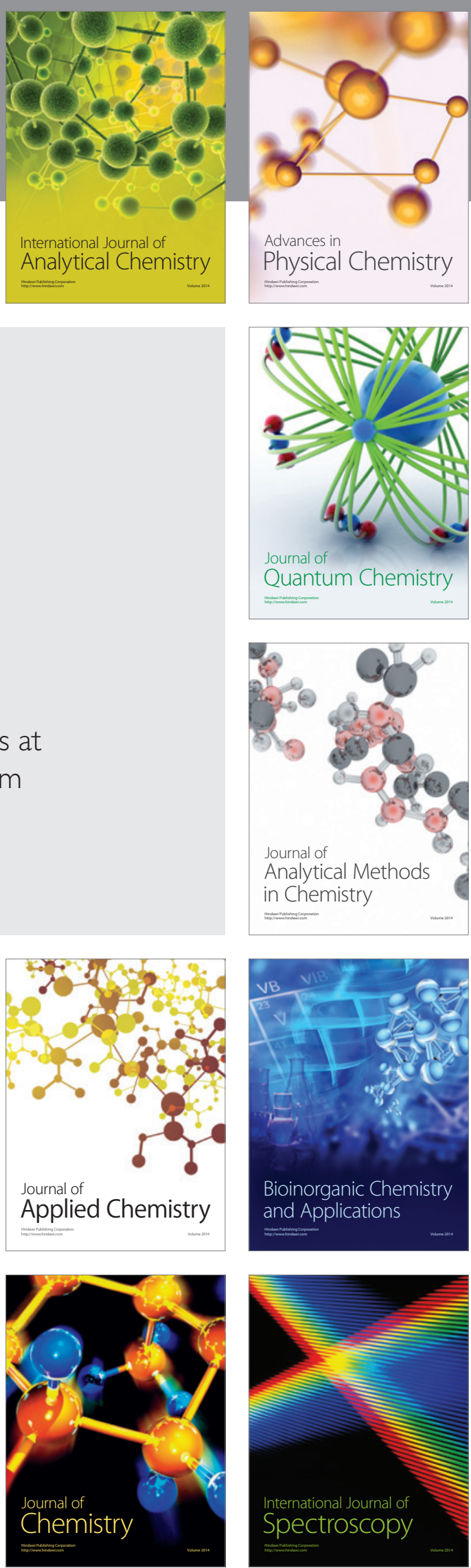